\title{
La evaluación de infraestruc- turas y edificios de biblioteca: Faulkner-Brown frente al cuestionario de la IFLA
}

José Pablo Gallo León*

Artículo recibido:

30 de octubre de 2014.

Artículo aceptado:

5 de noviembre de 2015.

\section{Resumen}

Se realiza una aproximación a la evaluación de edificios e infraestructuras de bibliotecas, centrándose especialmente en las académicas. A pesar del coste e importancia que para las bibliotecas tienen sus espacios, este tipo de evaluación ha sido descuidado hasta los últimos años. Aun ahora se encuentran pocos ejemplos de herramientas para efectuar estas evaluaciones. Por ello, se realiza una comparación entre dos modelos utilizables con este fin: un cuestionario de evaluación aplicable de forma universal y derivado del uso de los decálogos de Faulkner-Brown y McDonald; y el Questionnaire on Post-Occupancy Evaluation of Library buildings de la IFLA, debidamente adaptada. La evaluación se realiza

* Universidad de Alicante y Universidad de Murcia, Biblioteca de Educación, España jpablo.gallo@ua.es

INVESTIGACIÓN BIBLIOTECOLÓGICA, Vol.31, Núm.72, mayo/agosto, 2017, México, ISSN: 2448-8321. pp. 81-111 
sobre una biblioteca universitaria real, para valorar su idoneidad y posibilidades de aplicación práctica.

Palabras clave: Edificios de Biblioteca; Arquitectura Bibliotecaria; Bibliotecas Universitarias; Evaluación de Bibliotecas.

\section{Abstract}

Library buildings assessment: Faulkner-Brown vs. IFLA Questionnaire

José-Pablo Gallo-León

This paper examines the evaluation of library buildings, particularly the evaluation of academic libraries, by scrutinizing several approaches employed in recent years. Despite the importance and cost of the space for the libraries, evaluation of library buildings has been neglected until recently. Even now, there are few effective instruments for performing such assessments. Therefore, this paper provides a comparison of two models used for this purpose. We compare an assessment questionnaire based on the Faulkner-Brown and McDonald "commandments" to an adapted version of the Questionnaire on Post-Occupancy Evaluation of Library Buildings developed by IFLA. The evaluations are performed on a real university library in order to assess the suitability of these instruments and the scope of their practical application.

Keywords: Library Buildings; Library Architecture; Academic Libraries; Library Assessment; Library Evaluation

$\mathrm{R}_{\mathrm{n}}^{\mathrm{e}}$ esulta evidente que las bibliotecas, como entidad física de ladrillo y cemento, más que desapareciendo están evolucionando rápida y radicalmente su forma con los cambios tecnológicos, educativos y sociales de los últimos años. Las bibliotecas, representantes de una tecnología obsoleta como es el libro-códice, no son sustituidas, sino que conviven y se transforman con las TIC y gracias a ellas (Black y Dahlkild, 2011). De estar centradas y, por tanto, diseñadas en torno al objeto libro pasan a ser lugares culturales y sociales concebidos en torno a las personas y la prestación de servicios a las mismas. Se busca crear ese tercer lugar que decía Ray 
Oldenburg (1989, 1991 y 2000), ágoras o puntos de encuentro, a la manera de redes sociales físicas. En el caso de las bibliotecas académicas, también se pretende ofrecer espacios para el aprendizaje, más que espacios para la información. Consecuentemente, surge el problema de la valoración de los espacios bibliotecarios y su adecuación a estos modelos. Debemos discernir si los edificios que tenemos responden a estas expectativas planteadas y a nuestras necesidades reales.

Los edificios de bibliotecas son un recurso muy costoso que, como tal, debería ser evaluado y medido en su rendimiento. Sorprendentemente, y a pesar de la gran inversión que supone un edificio, tanto para su construcción como para su mantenimiento, no se han realizado durante mucho tiempo suficientes estudios empíricos sobre el éxito final de una nueva estructura (Shill y Tonner, 2004). Cualquier reducción en los gastos derivados de la infraestructura puede resultar fundamental, y el fracaso de un proyecto es un desastre para las finanzas de la institución. Por otra parte, los sistemas de gestión de calidad en bibliotecas se centran en la prestación de servicios y la satisfacción de los usuarios, sin profundizar convenientemente en la influencia que el entorno físico, el edificio, puede tener en la forma que damos ese servicio y puede afectar a la satisfacción del usuario.

Ante esta importancia de la evaluación de edificios para la correcta prestación del servicio y la eficiencia económica han surgido algunas iniciativas centradas especialmente en la evaluación postocupacional de la biblioteca. Entre ellas, destaca notablemente el cuestionario de evaluación desarrollado por la IFLA recientemente (IFLA. Library Buildings and Equipment Section, 2013). Con anterioridad se han utilizado otras herramientas con mayor o menor éxito, entre las que podemos encontrar la aplicación directa del decálogo de Faulkner-Brown nacido con una intención algo diferente pero semejante. Derivado de éste, se propuso un método de evaluación basado en estos mandamientos, pero evolucionados y adaptados (Gallo León, 2012). Ambos modelos pueden aplicarse sobre un caso concreto para comparar sus ventajas e inconvenientes.

\section{OBjetivos y METOdología}

El objetivo fundamental es la presentación y prueba de unas herramientas de evaluación de edificios de biblioteca que puedan ser utilizadas de forma sencilla. Un modelo debe aspirar a ser utilizable independientemente del tamaño de la instalación y su finalidad; esto es, aplicable universalmente.

Para ello, se toman dos modelos que pueden ser usados con formato de formulario, lo que les permite utilizarse en autoevaluaciones y encuestas con 
relativa sencillez, siendo manejado por un experto o una persona con conocimientos más limitados: el modelo propuesto por Gallo León (2012) frente al cuestionario desarrollado por la IFLA. Nos proponemos demostrar la viabilidad comparada de la aplicación práctica de ambos en casos reales. Deben ser fácilmente comprensibles y suficientemente rápidos de completar. Igualmente, si lo que interesa en la calidad es la prevención, estos formularios deben poder ser utilizados en la evaluación previa, además de la simultánea o posterior.

Se pueden evaluar fácilmente aspectos técnicos, puramente mecánicos, como el cumplimiento de los reglamentos de edificación. Pero lo que nos interesa es la evaluación de la infraestructura como biblioteca: su funcionalidad, adaptabilidad, atractivo, etc. Así, el cuestionario debe responder si el edificio se adapta a los modelos de biblioteca como ágora o punto de encuentro y de biblioteca como "contenedor agradable" (Gallo León, 2012). Según esto, los edificios deben ser ante todo flexibles, cajas que rellenemos, pero adaptados a su entorno, y extensibles, lo cual nos permitirá afrontar cualquier cambio o reto. Eso no tiene por qué significar que sean feos, sino al revés, además de tener que ser confortables. Hay que valorar, por tanto, la funcionalidad, eficiencia, eficacia y belleza del edificio.

Con este fin se considerarán los dos modelos citados, adaptando el cuestionario de la IFLA para que pueda hacerse una comparación efectiva entre ambos, pues su concepción inicial es más de lista de comprobación o checklist. En cuanto al otro modelo, nace del análisis crítico de otras iniciativas de evaluación de espacios bibliotecarios, así como del entorno de calidad bibliotecaria, mediante una búsqueda bibliográfica exhaustiva, lo que nos permite el establecimiento de un marco teórico.

De este conocimiento se infiere la propuesta de una nueva metodología de evaluación, tomando como ejemplo la aplicación como herramienta de los decálogos de Faulkner-Brown y su derivado de McDonald; se genera como uno refundido y actualizado, que también pueda ser utilizado como cuestionario y, por tanto, herramienta de evaluación.

\section{LA CALIDAD DE LAS BIBLIOTECAS Y LA EVALUACIÓN DE SUS EDIFICIOS}

La mayoría de los métodos de evaluación aplicados a las bibliotecas tiene única o principalmente en consideración la evaluación de los servicios. García Caro (2005) afirmaba que esto es desde que Maurice Line dijese que la calidad de una biblioteca se mide por su capacidad de cumplir con las necesidades de información. Michael K. Buckland (citado por García Caro, 2005) aseguraba que se podían asimilar la capacidad y la calidad debido 
a que ambas son difíciles de medir directamente. Por eso hay que buscar otros elementos sustitutivos que nos permitan medir la calidad a través de ellos, para lo cual se han usado mayoritariamente ciertos servicios fácilmente mensurables, como el préstamo interbibliotecario.

La evaluación del espacio bibliotecario se limitaba en un principio a su relación con las colecciones y su crecimiento, no en relación a los clientes (usuarios), aunque sí quedó una gran premisa, a veces olvidada: se evalúa con un fin, con un objetivo, y no debería realizarse sin él (Roberts y Weaver, 2006). La evaluación no es el fin, es el medio. Entonces deberíamos definir el porqué y el para qué de la evaluación.

¿Por qué evaluamos? Para conocer:

- La comodidad del espacio;

- Su facilidad de uso;

- La eficiencia energética e impacto ambiental;

- Su adaptabilidad;

- La adecuación a la variedad de necesidades;

- Datos de primera mano sobre las necesidades de los usuarios, y

- (Para valorar) la efectividad del entorno en los resultados de estudio e investigación.

¿Para qué evaluamos? Adaptando las razones esgrimidas por los mismos autores, evaluamos con la finalidad de:

- Medir los resultados y la eficiencia del espacio;

- Obtener criterios para la variación en las infraestructuras o la construcción de algunas nuevas, y

- Obtener un conocimiento más profundo de la arquitectura y gestión de espacios bibliotecarios.

Se puede argumentar que el alto coste de los edificios e infraestructuras bibliotecarias, tanto en lo que se refiere a su construcción como a su mantenimiento, ya es de por sí razón suficiente para evaluarlos. Además, los cambios que el modelo de biblioteca está experimentando en los últimos años también nos deben motivar a preguntarnos si nuestro edificio responde a estas necesidades sobrevenidas. Las colecciones digitales han reducido la presión sobre el espacio bibliotecario, particularmente en las bibliotecas académicas y de investigación, liberándolo para otros usos, al tiempo que para los gestores de las respectivas organizaciones pone en duda la necesidad de la biblioteca física. 
La evaluación de una biblioteca, que busca la mejora del servicio a través de su análisis como herramienta para la planificación, debe tener unos fines concretos que justifiquen la misma, en sí larga y compleja (Fuentes Romero, 1999). De esto se deriva una tipología de evaluación, que en el caso de edificios puede ser para:

- Conocer el nivel de calidad alcanzado por el servicio o, en este caso, del edificio y/o proyecto;

- Compararlo con otros edificios similares;

- Justificar la propia existencia de la infraestructura, e

- Identificar las causas de fallos o ineficiencias.

La evaluación de la calidad puede medir diferentes aspectos del diseño, adaptando a Khan (2009):

- Su emplazamiento: accesibilidad, tráfico cercano, topografía, disponibilidad, visibilidad, seguridad de los accesos, capacidad de crecimiento, coste, infraestructura necesaria, sinergias con otros equipamientos, orientación, localización aceptable para los usuarios;

- Adecuación urbanística;

- Su estética;

- Su funcionalidad;

- Su accesibilidad;

- Su impacto medioambiental, y

- Costes de mantenimiento.

La evaluación del edificio no se restringe a la concepción cuantitativa, a la medición de inputs o recursos, sino que se asocia a la medición del impacto si consideramos el espacio bibliotecario dentro del nuevo paradigma, ya como promotor del aprendizaje y la investigación en las bibliotecas universitarias o como espacio de intercambio, socialización y fomento de la cultura y el conocimiento en las públicas.

Resulta evidente la dificultad de la evaluación del rendimiento de una infraestructura más allá de criterios meramente técnicos. Esto hace que la mayoría de los indicadores bibliotecarios que encontramos disten mucho de ser útiles para el propósito de evaluar los edificios desde este punto de vista del impacto.

Como es sabido, la preocupación por la búsqueda de la calidad y la satisfacción del usuario ha sido especialmente activa en el entorno bibliotecario, proliferando diversas técnicas para conseguirla, en forma de iniciativas y proyectos de evaluación de servicios y recursos bibliotecarios. Podemos 
señalar, entre otros, LibECON, el Benchmarking, EQUINOX-Library Perfomance Measurement and Quality Management System, ICOLC-Guidelines for Statistical Measures of Usage of Web-Based Information Resources, ARL E-Metrics Project, COUNTER o LibQUAL+. No obstante, en su profundo estudio de la medición del impacto de las bibliotecas sobre los resultados de la universidad, Lindauer (1998) evidenciaba la escasez hasta entonces de indicadores sobre los edificios, infraestructuras y su rendimiento, aunque están casi siempre presentes en los estudios, generalmente en forma de horas de apertura o metros cuadrados por usuario. Es decir, en una forma que no nos indica de ninguna manera el rendimiento del edificio, su contribución a los fines de la universidad y la biblioteca, y la satisfacción de sus clientes (usuarios y personal) con el mismo. La medición de la satisfacción de estos clientes debe ser la clave para evaluar el éxito en la concepción de la biblioteca.

Resulta sorprendente el escaso interés suscitado hasta hace pocos años por la evaluación de infraestructuras en un entorno tan preocupado por la calidad, con excepciones como el británico Higher Education Design Quality Forum, sostenido por el RIBA (Royal Institute of British Architects) y Universities $U K$, entre otros. Esto a pesar de la enorme influencia del coste de los edificios sobre los presupuestos de la biblioteca, así como de la importancia, señalada por Forrest y Bostick (2012: 15) de crear una cultura de la evaluación de las infraestructuras bibliotecarias para mejorar los servicios a los usuarios.

Aún no hay un modelo prevalente en el mundo bibliotecario para la evaluación de los espacios de aprendizaje a pesar de que la evaluación de los espacios en general es una inquietud recogida últimamente en conferencias especializadas sobre evaluación, como en las bienales Library Assessment Conferences de la ARL (Association of Research Libraries). Y es que la evaluación de los espacios bibliotecarios es una preocupación relativamente reciente (Nitecki, 2011). Hasta ahora sólo se recogían datos, pero no se hacía el trabajo interpretativo que requiere la evaluación. Si queremos saber si la inversión realizada en las nuevas instalaciones ha contribuido efectivamente al desarrollo educativo de los estudiantes, el simple recuento de la puerta no nos va a aclarar demasiado. Tanto Lippincott (2006) como Nitecki (2011) indican que ya no basta con saber si las instalaciones se usan, son confortables o suficientes para la comunidad. Queremos saber si favorecen el aprendizaje, pero esto es muy complejo de medir. Se puede valorar la experiencia de aprendizaje y enseñanza en ellos a través de, por ejemplo, encuestas. Pero el aprendizaje es una actividad personal que difícilmente puede ser evaluada comparativamente entre un espacio y otro, sobre todo cuando ambos son eficaces a su modo. 
Dicho esto, no vamos aquí a realizar una panorámica exhaustiva de los diferentes sistemas de indicadores y recolección de estadísticas que traten las infraestructuras, tanto por el espacio requerido como por poder ser consultado en otros trabajos (Gallo León, 2012).

Además de estas herramientas más o menos sistemáticas, para la evaluación de edificios, podemos recurrir a otras de más complicada aplicación, como el conocimiento de manuales sobre construcción de bibliotecas, normas y pautas existentes, o uso de consultores bibliotecarios que tengan estos conocimientos por nosotros. Creemos que el uso de consultores bibliotecarios merecería, por sí solo, un estudio más profundo sobre su utilidad, a pesar de ser una figura casi inexistente en España.

En lo que se refiere a las normas internacionales, obviando la meramente estadística ISO 2789, la ISO 11620 de Indicadores de rendimiento bibliotecario tiene algunos indicadores dedicados a las instalaciones que miden la disponibilidad y uso de las instalaciones, sin que se pueda deducir de ello el éxito de unas instalaciones en su apoyo a los objetivos de la organización, sea el aprendizaje, la investigación o el ocio, a pesar de haber sido utilizadas en algunos sitios, como en Trento (Bellini, 2000), con buen resultado.

El informe técnico ISO/TR 11219:2012 Qualitative conditions and basic statistics for library buildings (space, function and design) nos puede servir para realizar una comparación con la norma de mobiliarios, equipamientos e instalaciones, incluyendo las superficies necesarias para su acomodo así como el de los usuarios. Sin embargo, no entra tanto en superficies totales, aunque realice un interesante desglose general de la variedad tipológica necesaria.

Finalmente, la ISO 16439 Methods and procedures for assessing the impact of libraries surge para crear instrumentos de evaluación del impacto de los servicios bibliotecarios en individuos y comunidades, suponiendo un avance. De esta forma, trata sobre la evaluación del espacio bibliotecario en dos apartados: en las evidencias inferidas y, más específicamente, entre los ejemplos de métodos (apartado 9.2.3).

Más identificada a nuestra metodología de estudio encontramos la evaluación postocupacional o POE (Post-Occupancy Evaluation). Estrictamente hablando, la evaluación postocupacional es el proceso de evaluación sistemática de los edificios después de que hayan sido construidos y habitados u ocupados por un tiempo indeterminado. POE se puede definir también, adaptando a Preiser (1995), como el proceso de comparación sistemática del rendimiento del edificio con respecto a los criterios previstos o programa de necesidades de la biblioteca. La POE evolucionó en torno al 2000 hacia la BPE (Building Performance Evaluation) o evaluación del rendimiento de los edificios. 
Con la POE, la evaluación de un edificio deja de ser meramente técnica al centrarse en el concepto de rendimiento del mismo, en donde se vincula el éxito de una infraestructura a lo largo del tiempo con su capacidad de satisfacer las necesidades de sus ocupantes, básicamente cuestionándolos y valorando su desempeño en el edificio estudiado. Por ello, la fuente es subjetiva, basada en opiniones y percepciones, pero esto no le resta valor.

Si la POE evalúa algo que ya existe, tiene sentido, sobre todo, en el marco de la comparación y el aprendizaje. Nos puede ayudar a mejorar nuestro centro, pero sobre todo debe proporcionar un punto de referencia para posteriores diseños, ya que sobre un edificio recién construido resulta inviable su reforma a corto plazo. En esto se alinea con otras tipologías de evaluación posterior. Es una parte tan importante como frecuentemente subestimada del proceso (McDonald, 2007), que supone la oportunidad de evaluar si el edificio responde a lo planificado, a las expectativas, o si debe ser modificado. Igualmente, Bisbrouck y Enright (citados por Boekhors y Scholle, 2002) subrayan las ventajas de evaluar edificios de bibliotecas después de su finalización mediante el uso de métodos estandarizados o de un cuestionario, como haremos a continuación.

Durante mucho tiempo las evaluaciones posteriores no fueron numerosas. Así, en España, el informe sobre arquitectura bibliotecaria entre 1995 y 1999 realizado por REBIUN (2000: 8), decía expresamente que "en ninguno de los [diez] casos recogidos se ha interrogado al usuario acerca de su opinión sobre la biblioteca que frecuenta y el juicio que le merece su instalación". Esto está cambiando, como podemos ver en las abundantes experiencias de POE recogidas en la sesión de 2012 de la Sección de Edificios y Equipamientos Bibliotecarios de la IFLA.

A nivel quizás anecdótico, la aparición de los edificios en revistas y, más aún, los premios arquitectónicos, puede ser considerada como una evaluación posterior de facto. Aunque estos suelen proceder del ámbito arquitectónico, podemos recordar los premios anuales de la ALA y el SCONUL Design Award. En este sentido, resulta especialmente notable la iniciativa de la $L i$ brary Journal para identificar bibliotecas recientes que puedan servir como ejemplos o modelos a imitar por su diseño, conocidas como "New Landmark Libraries" (Library Journal, 2011). Para ello, utilizaron criterios que no dejan de recordar a los de Faulkner-Brown: la excelencia del diseño y construcción en general, la respuesta al entorno y restricciones de la comunidad, sostenibilidad, funcionalidad, innovación, y belleza y deleite. 
La aparición del Cuestionario para la Evaluación Postocupacional de la Sección de Edificios y Equipamientos Bibliotecarios (Questionnaire on Post-Occupancy Evaluation of Library buildings) de la IFLA (IFLA. Library Buildings and Equipment Section, 2013) provoca el replanteamiento de cualquier iniciativa al respecto; de forma más inmediata, la viabilidad de la propuesta ligeramente anterior que en este artículo exponemos. En primer lugar, resulta digno de alabanza el esfuerzo realizado por la sección sobre la evaluación de edificios, desatendida, como hemos visto, por mucho tiempo. El trabajo de esta sección se complementa con otros documentos de gran peso, principalmente las IFLA Library Building Guidelines: Developments E Reflections de 2007. Además, miembros de esta sección han participado en la elaboración del otro gran documento sobre edificios de bibliotecas aparecido en un breve lapso de tiempo: la Instrucción Técnica ISO/TR 11219:2012. Con ellos, el interesado en la materia cuenta con un gran respaldo teórico, inexistente hace un lustro.

Con el cuestionario se dispone de una herramienta que nos permite examinar nuestro edificio de forma sistemática. De esta forma obtendremos una impresión clara de su correcto desempeño como instrumento del servicio bibliotecario. Tiene una clara vocación universal, sirviendo tanto para grandes o pequeñas bibliotecas, de cualquier clase, aunque haya partes exclusivas de una tipología u otra. Por eso mismo, puede ser utilizado de forma completa o parcial. Está destinado a su uso por bibliotecarios gestores, diseñadores o cualquier interesado en el tema. Así, permite evaluar nuestro centro con diversos objetivos: previsión de cambios, justificación de los mismos, información para la toma de decisiones en general, etc. Su finalidad principal y declarada es la identificación de buenas prácticas en el diseño de edificios bibliotecarios. En la línea teórica de la POE, esto permitirá que, a través de la comparación con otros centros, podamos mejorar el diseño del nuestro evitando errores y aplicando aciertos. De esta forma, previamente al diseño de un espacio bibliotecario se puede aplicar este cuestionario a centros semejantes para mejorar nuestra propuesta.

Está estructurado en cuatro secciones: aspectos generales, edificio, servicios y cuestiones finales. Se desarrolla como una serie de preguntas, la mayoría de las cuales se pueden responder con sí/no. Interroga sobre puntos básicos en aspectos de la accesibilidad, seguridad, sostenibilidad, mobiliario, servicios prestados y funcionamiento de las infraestructuras. Para comprobar sus posibilidades, lo aplicaremos en este mismo artículo sobre una biblioteca real, aunque obviaremos algunas partes del mismo, como los datos generales del centro. No obstante, el cuestionario completo está fácilmente accesible en la red (IFLA. Library Buildings and Equipment Section, 2013). 


\section{Propuesta y APlicación de Un MOdelo de EVAluación BaSAdo EN}

\section{FAULKNER-BROWN}

Frente a este cuestionario, proponemos la aplicación de una versión evolucionada y adaptada del cuestionario de Faulkner-Brown, que se desarrolló en un anterior trabajo de investigación (Gallo León, 2012), tras un largo periodo de análisis, reflexión y síntesis. En primer lugar, se pensó que para realizar evaluaciones de edificios lo más conveniente sería desarrollar un sistema de indicadores. Recordemos que un indicador es un

parámetro de evaluación y medición de un producto o servicio que, tras el análisis de resultados cuantitativos-cualitativos y la comparación con modelos aceptados, sirve para determinar el grado de calidad del producto o servicio sometido a un proceso de evaluación. Su utilidad proviene de la capacidad de comparar el nivel de calidad de un parámetro o característica con respecto a unos niveles establecidos previamente (Játiva Miralles, 2004: 32).

De esta forma, las posibilidades de tener unos indicadores satisfactorios son escasas, porque nos tendríamos que centrar en criterios numéricos y de comparación con el canon o centros semejantes. Aún con la ventaja de su objetividad frente a la subjetividad de otros métodos de búsqueda de la satisfacción, así sólo obtendríamos aspectos parciales del desempeño del edificio. De esta forma seguiríamos la estela de otras evaluaciones basadas en estos criterios numéricos, algo que, según el Higher Education Design Quality Forum, puede ser contraproducente (Enright, 2002). Con estos medios resulta sencillo medir la ocupación de las salas o el número de puestos en relación a una ratio, pero no la satisfacción del usuario con estos puestos o si el diseño de los mismos y de las salas ayudan a la consecución de los objetivos de la institución, por ejemplo, el aprendizaje en las bibliotecas académicas.

Para evaluar la satisfacción de los usuarios con el edificio y sus equipamientos tendríamos que desarrollar indicadores que midiesen estos parámetros. Para ello nos basaríamos en la percepción de los clientes (usuarios y personal), lo cual nos lleva a una subjetividad difícilmente compatible con la mensurabilidad que debe caracterizar a los indicadores. Estamos midiendo opiniones, no certezas. Se debe diferenciar entre una calidad técnica, objetiva, y otra funcional, que es a juicio del usuario y que está en función de sus expectativas. Raramente los indicadores de satisfacción examinan estos aspectos.

Por otra parte, las experiencias de interrogación a los usuarios sobre la opinión de los edificios han escaseado, quizás por el coste y complejidad de estos estudios (Mittler, 2008). Últimamente encontramos aportes de gran 
interés, como el eficaz trabajo de Hebert y Chaney (2012) para el rediseño en la iluminación de su biblioteca. Igualmente, y enlazando esto con iniciativas para contar con los ciudadanos y usuarios en el diseño de nuevos centros, podemos reseñar algunas modélicas, como la de la Biblioteca Pública de Helsinki (Miettinen, 2013).

Por todo ello, se propuso un formulario de evaluación que se fijase en parámetros basados en la experiencia y en la comparación con otros ejemplos. Esto quizás cargue de cierta subjetividad ante la necesaria intervención personal, pero se debería ver compensada con un mayor grado de conocimiento empírico del/los ejecutantes: a mayor experiencia de los mismos, mayor objetividad de los resultados.

Estos parámetros se van a extraer de un modelo bien conocido: el decálogo de Faulkner-Brown y su evolución con McDonald, que vemos más abajo. Si bien es cierto que la satisfacción de las personas que lo usan es lo que mejor determina la calidad del edificio, como señala Krempe (2002), sigue siendo efectiva la utilización como guía de los famosos mandamientos de FaulknerBrown. De hecho, este autor los utiliza en su análisis del edificio de la British Library en St. Pancras de forma efectiva, por lo que lo vamos a seguir en buena medida. Con ello no hacía más que seguir al mismo Faulkner-Brown, quien pensaba que su decálogo podía usarse tanto para el diseño de una biblioteca nueva como para la evaluación de una ya existente (Vélez Salas, 2002). En el mismo sentido, las Normas y Directrices para Bibliotecas Universitarias $y$ Científicas de REBIUN (1999) recomiendan su uso en el apartado sobre infraestructuras. También una encuesta en Alemania (Mittler, 2008) utilizó el muy semejante decálogo de $\mathrm{McDonald}$ como base para la elaboración de una encuesta de evaluación distribuida por las bibliotecas universitarias.

Los criterios de Faulkner-Brown han sido con el tiempo cuestionados y han experimentado una evolución, obra del propio autor o del citado McDonald, quien los desarrolló en una serie de artículos con relación a las cualidades del CRAI. Si comparamos ambas listas, vemos:

\begin{tabular}{|l|l|}
\hline \multicolumn{1}{|c|}{ McDonald } & \multicolumn{1}{c|}{ Faulkner-Brown } \\
\hline Funcional & Flexible \\
\hline Adaptable & Compacto \\
\hline Accesible & Accesible \\
\hline Variado & Expansible \\
\hline Interactivo & Variado \\
\hline Favorable & Organizado \\
\hline
\end{tabular}




\begin{tabular}{|l|l|}
\hline Adecuado al medio ambiente & Confortable \\
\hline Seguro & Estable medioambientalmente \\
\hline Eficaz & Seguro \\
\hline $\begin{array}{l}\text { Adecuado para la tecnología de la in- } \\
\text { formación }\end{array}$ & Eficiente \\
\hline Impactante & Ecológico \\
\hline
\end{tabular}

Tabla I. Comparación de los decálogos de Faulkner-Brown y McDonald

McDonald (2001) pensaba, con razón, que el decálogo podía resultar insuficiente, y recomendaba tomar en consideración otros criterios, como la iluminación, el ruido, la adaptación a las personas con discapacidad, la seguridad, cuestiones ecológicas, la orientación (señalización) o la estética. En otro artículo (McDonald, 2006) indicaba la necesidad de la revisión del decálogo original de Faulkner-Brown debido a los cambios producidos en las bibliotecas a lo largo del tiempo, pues habían variado el sentido de las definiciones originales.

Ambos listados han sido criticados por su ambigüedad y se puede afirmar que son algo imprecisos en la definición de los criterios. Ciertamente, resulta muy difícil aplicarlos directamente en la evaluación si queremos contar con cierta objetividad. Sin embargo, la propia sistematización en leyes que estos mandamientos suponen nos pueden indicar un alto grado de madurez de la investigación en este campo. Además, ya considerábamos que una cierta subjetividad era irremediable si estábamos tomando en consideración la satisfacción y, por tanto, las opiniones. Quizás por ello McDonald (2006) prefería hablar de "cualidades" mejor que de "mandamientos", pues lo que pretendía era proponer unas características-tipo a las que debían aspirar las bibliotecas.

Edwards y Fisher (2002) añaden como criterios la sostenibilidad y que eleve el ánimo. La primera fue también incluida por Faulkner-Brown en sus revisiones y resulta obvia en estos momentos, dada la corriente de interés en las bibliotecas verdes que marca la actualidad en estas materias relacionadas con las infraestructuras. La segunda, que eleve el ánimo ("uplifting to the spirit"), se puede asimilar en parte al factor Oomph de McDonald (impactante), pero pretende ir más allá: que la arquitectura ayude a que la experiencia del lector como usuario sea plenamente satisfactoria desde un punto de vista inmaterial, espiritual, algo que también podría incluirse en el confort.

Señalan los mismos autores, además, que el orden e importancia de los diferentes puntos, en este caso 12, dependerá de la tipología de la biblioteca, sin anteponer unos a los otros, algo en lo que no podemos estar plenamente de acuerdo. Creemos más bien que se debe dar un orden según su importancia, tal como hicieron los propios Faulkner-Brown y McDonald, sabiendo 
que todos estos factores tienen un gran peso y se debe intentar alcanzar entre ellos un compromiso cuando entren en conflicto.

Hay, además, otras versiones semejantes, bien basadas en el modelo, bien paralelas, que refuerzan la idea de su uso para la evaluación, como Carrión Gútiez (2001) en su Manual, Mason (1980) en su conocido Mason on Library Buildings, el no menos conocido Metcalf (citado por Domínguez Martínez, 2002) o, en un plano muy próximo a lo que pretendemos, los criterios utilizados para el SCONUL Design Award son también semejantes. Finalmente, como versión reducida y contrapuesta de los "mandamientos", pues aborda el tema en negativo y con cierto humor, tenemos los Siete pecados capitales de la arquitectura de bibliotecas públicas de Schlipf y Moorman (1998).

Con todo ello, se propuso una readaptación de las listas de Faulkner-Brown y McDonald, insistiendo en aquellos aspectos que más nos interesan, refundiendo los que consideramos muy próximos y añadiendo aquellos que nos parecen necesarios. También se pretendió enriquecer las definiciones con un mayor desarrollo de cada punto, que no cabe aquí pero que está disponible de forma libre (Gallo León, 2012). De esta forma, creamos a la vez una herramienta y un nuevo decálogo que, al igual que los anteriores, se ordena según la importancia percibida. Así, el nuevo decálogo propuesto para su aplicación como herramienta de evaluación sería:

1. Adaptable, término preferible a flexible, pues se ajusta más a la idea de que se adapte a los desafíos de futuro, cambiando su forma según las necesidades.

2. Variado, cualidad de extremada importancia en el momento ac tual, en el que necesitamos espacios muy diversos para múltiples necesidades.

3. Funcional, lo que implica que sea fácil de usar, legible y perdurable, para lo que tiene que ser también una biblioteca ordenada.

4. Accesible, en todos los sentidos: accesibilidad para personas con discapacidad, accesibilidad psicológica (que invite a ser usada, atractiva, transparente, con poder simbólico, etc.), accesibilidad ex terna (situación central, visibilidad, que sea fácil llegar a ella, etc.) y accesibilidad interna (señalizada, buena circulación, también legi ble).

5. Confortable, en todos los sentidos: iluminación, climatización, acús tica, mobiliario, estética, organización y amplitud.

6. Eficaz y eficiente: que funcione sin un gran gasto de personal, de mantenimiento o energético. Abarca la compacidad, por su gran 
repercusión en los costes de mantenimiento y energéticos, y la ex pansibilidad, aspecto este último discutible por su dificultad real.

7. Ecológico, lo que implica algo más que el edificio, pero en lo que éste resulta fundamental en aspectos estructurales, constructivos y técnicos

8. Seguro, en todas sus acepciones: de cara a su uso y frente amenazas accidentales o provocadas

9. Estético e impactante. El factor Oomph de McDonald: si el edificio resulta cautivador, llamativo e identificativo.

10. De calidad, bajo la eterna premisa de que lo barato sale caro.

Como en el caso citado de McDonald (2001), en una evaluación completa hay que tomar en consideración algunos aspectos más, como:

- Datos generales del edificio: año de construcción, superficies, arquitecto responsable, presupuesto y coste final, plazo de ejecución, metros cuadrados y lineales, número de salas y de plantas, existencia de depósito, etc.

- Concepción arquitectónica, si se dispone de ella, a través de la memoria o proyecto del arquitecto.

- Implicación de bibliotecarios y otros actores en el diseño: grado de participación de los bibliotecarios y de otros grupos interesados en el proyecto, como usuarios, miembros de la comunidad (alumnos y profesores o asociaciones de vecinos, por ejemplo), miembros con poder de decisión política, etc.

- Grado de cumplimiento de las ratios o al menos, de las medias. Para ello puede emplearse la comparación con las recomendaciones internacionales y locales (ver, por ejemplo, las citadas en el Informe ISO/TR 11219) o con las medias de estadísticas regionales/ nacionales.

Sobre esta lista se crea un modelo de formulario para la evaluación en el que se aplica un sistema de puntuación con una escala Likert del 1 al 5, en el que uno sería muy malo, dos malo, tres regular, cuatro bueno y cinco muy bueno. Con ello se pueden obtener puntuaciones medias de las bibliotecas. Si un apartado se desglosa para su mejor valoración, la puntuación del mismo sería la media de las puntuaciones de estos subapartados. De esta forma, se obtendría una media final de entre 1 y 5 , en el que el umbral de la calidad sería 4-5, y 2 o menos detectaría problemas muy graves. Además, se puede obtener una segunda puntuación total, multiplicando los resultados de cada apartado por 
un coeficiente y sumando los resultados. Así, Adaptable se multiplicaría por 10, Variado por nueve, y así sucesivamente hasta De calidad, que se multiplicaría por 1 .

De esta manera, el formulario tendría la forma que presentamos a continuación, aquí en su aplicación práctica a la Biblioteca General de la Universidad de Alicante:

\begin{tabular}{|c|c|c|c|c|c|c|c|}
\hline Concepto & \multicolumn{5}{|c|}{ Puntuación parcial } & \multirow{2}{*}{$\begin{array}{r}\text { Puntuación } \\
4\end{array}$} & \multirow{2}{*}{$\begin{array}{r}\begin{array}{r}\text { Puntuación } \\
\text { ponderada }\end{array} \\
40\end{array}$} \\
\hline $\begin{array}{l}\text { 1.Adaptable (permite una fácil } \\
\text { adaptación de los espacios, } \\
\text { flexible). }\end{array}$ & 1 & 2 & 3 & 4 & 5 & & \\
\hline 2. Variada. & 1 & 2 & 3 & 4 & 5 & 3 & 27 \\
\hline 3. Funcional. & & & & & & 2.75 & 22 \\
\hline $\begin{array}{l}\text { Interactiva (facilita el encuentro } \\
\text { de los servicios y las personas). }\end{array}$ & 1 & 2 & 3 & 4 & 5 & 2 & \\
\hline Fácil de usar. & 1 & 2 & 3 & 4 & 5 & 3 & \\
\hline $\begin{array}{l}\text { Organizada (se encuentran las } \\
\text { cosas). }\end{array}$ & 1 & 2 & 3 & 4 & 5 & 3 & \\
\hline Perdurable/robusta. & 1 & 2 & 3 & 4 & 5 & 3 & \\
\hline 4. Accesible. & & & & & & 3.7 & 25.9 \\
\hline $\begin{array}{l}\text { Accesibilidad externa (fácil de } \\
\text { encontrar, invita a entrar...). }\end{array}$ & 1 & 2 & 3 & 4 & 5 & 4 & \\
\hline $\begin{array}{l}\text { Accesibilidad interna (sencillo } \\
\text { moverse dentro, bien señalizada, } \\
\text { adecuadas vías de circulación } \\
\text { vertical y horizontal...). }\end{array}$ & 1 & 2 & 3 & 4 & 5 & 3 & \\
\hline $\begin{array}{l}\text { Adaptada al uso por personas } \\
\text { con discapacidad. }\end{array}$ & 1 & 2 & 3 & 4 & 5 & 4 & \\
\hline 5. Confortable. & & & & & & 2.8 & 16.8 \\
\hline Iluminación. & 1 & 2 & 3 & 4 & 5 & 4 & \\
\hline Climatización. & 1 & 2 & 3 & 4 & 5 & 2 & \\
\hline Acústica. & 1 & 2 & 3 & 4 & 5 & 2 & \\
\hline $\begin{array}{l}\text { El mobiliario: ergonomía y } \\
\text { comodidad. }\end{array}$ & 1 & 2 & 3 & 4 & 5 & 3 & \\
\hline $\begin{array}{l}\text { Espacio: orden, facilidad para } \\
\text { moverse, amplitud... }\end{array}$ & 1 & 2 & 3 & 4 & 5 & 3 & \\
\hline 6. Eficaz y eficiente. & & & & & & 3.7 & 18.5 \\
\hline Mantenimiento sencillo. & 1 & 2 & 3 & 4 & 5 & 4 & \\
\hline
\end{tabular}




\begin{tabular}{|c|c|c|c|c|c|c|c|}
\hline Compacta. & 1 & 2 & 3 & 4 & 5 & 3 & \\
\hline Expansible. & 1 & 2 & 3 & 4 & 5 & 4 & \\
\hline 7. Ecológico. & & & & & & 3 & 12 \\
\hline Estructural/constructivo. & 1 & 2 & 3 & 4 & 5 & 3 & \\
\hline Técnicamente. & 1 & 2 & 3 & 4 & 5 & 3 & \\
\hline 8. Seguro. & & & & & & 2.5 & 7.5 \\
\hline $\begin{array}{l}\text { Sistemas de protección de } \\
\text { personas y documentos. }\end{array}$ & 1 & 2 & 3 & 4 & 5 & 2 & \\
\hline Salubridad medioambiental. & 1 & 2 & 3 & 4 & 5 & 3 & \\
\hline 9. Estético e impactante. & & & & & & 4.4 & 8.8 \\
\hline $\begin{array}{l}\text { Si el edificio le resulta cautivador } \\
\text { o estéticamente agradable. }\end{array}$ & 1 & 2 & 3 & 4 & 5 & 4 & \\
\hline $\begin{array}{l}\text { Si el edificio resulta llamativo, al } \\
\text { margen de su valoración estética. }\end{array}$ & 1 & 2 & 3 & 4 & 5 & 5 & \\
\hline $\begin{array}{l}\text { Si el edificio resulta identificati- } \\
\text { vo, al margen de su valoración } \\
\text { estética. }\end{array}$ & 1 & 2 & 3 & 4 & 5 & 4 & \\
\hline 10. De calidad. & & & & & & 3 & 3 \\
\hline Calidad estructural & 1 & 2 & 3 & 4 & 5 & 4 & \\
\hline $\begin{array}{l}\text { Calidad de las terminaciones y } \\
\text { acabados. }\end{array}$ & 1 & 2 & 3 & 4 & 5 & 2 & \\
\hline Calidad de los materiales. & 1 & 2 & 3 & 4 & 5 & 3 & \\
\hline Calidad del mobiliario. & 1 & 2 & 3 & 4 & 5 & 3 & \\
\hline \multicolumn{6}{|c|}{ TOTALES: } & 2.68 & $\begin{array}{r}181.5 / \\
275\end{array}$ \\
\hline
\end{tabular}

El estudio completo de una biblioteca ocuparía demasiado espacio (tanto como este propio trabajo), por lo que se remite a un estudio ya realizado (Gallo León, 2012) sobre la Biblioteca General de la Universidad de Alicante. Por ello, se utiliza esta misma biblioteca como referencia para el otro cuestionario que tomamos en consideración: el Questionnaire on Post-Occupancy Evaluation of Library buildings.

Obviamos, pues, los aspectos numéricos, de adaptación a la norma, concepción arquitectónica, etc. Sólo comentar su correcta adaptación a la norma, de acuerdo al poco exigente pero realista Decreto sobre Creación y Reconocimiento de universidades, las pautas REBIUN, y la media REBIUN. Con 15.021 $\mathrm{m}^{2}$ la Biblioteca General supone el elemento diferenciador de estos datos de 
superficie. Su presencia permite que la Universidad de Alicante cuente con unas superficies y número de puestos que podemos considerar como más que aceptables, y en línea con otras universidades semejantes.

En cuanto a la puntuación obtenida por la biblioteca aplicando el modelo, vemos en la tabla que da una media de 2.68 o una puntuación ponderada de 181.5 sobre 275 , cifras aceptables. La valoración final del edificio en su conjunto debe ser positiva, sobre todo por la flexibilidad demostrada de los espacios. Su gran volumen y su perfil rectangular permiten y han permitido ya grandes reformas con coste contenido.

\section{APLICACIÓN Y COMPARACIÓN DEL FORMULARIO IFLA}

Para que la comparación entre ambos formularios fuese más efectiva, hemos optado por realizar una pequeña adaptación sobre el mismo que en ningún momento afecta a su concepción y espíritu. Se toman las preguntas como unas cuestiones a las que se puede aplicar una escala de Likert idéntica, tomándolas con un criterio de suficiencia, no de bipolaridad. De esta forma, no se responde sí o no, sino que se valora hasta que punto con lo que se cuenta en la biblioteca resulta suficiente para cumplir los requisitos de la pregunta. Creemos que esto facilita el uso del formulario y permite su utilización más sencilla como encuesta, además de ayudarnos en esta comparación. Por eso mismo, algunas cuestiones se han modificado o eliminado (el cuestionario lo permite), aunque otras cuestiones que no admiten esta puntuación se han dejado como desarrollo explicativo de las puntuaciones. Las cuestiones cuyo enunciado ha debido ser variado levemente, sin afectar a su fondo, aparecen indicadas con un asterisco $(*)$.

En este formulario no estableceremos una puntuación ponderada, pues en ningún lugar se señala la prevalencia de una cuestión y/o apartado sobre los demás. Además, hemos obviado los apartados de Datos y cifras y otros referidos a otras tipologías bibliotecarios, por considerarlos innecesarios en este caso.

Se ha conservado el apartado dedicado a Mobiliario, a pesar de que en el formulario propio está expresamente excluido, pero se han reducido notablemente los puntos dedicados a Servicios para no adulterar en exceso los resultados comparativos entre ambos cuestionarios. Así, se han conservado las referencias a las áreas de la biblioteca (variedad, utilidad...), eliminando las preguntas sobre colecciones, estanterías o automatización, que se alejan totalmente de lo cuestionado en la otra lista. Obviamente se han eliminado las referencias a zonas infantiles y se han adaptado las de zonas para jóvenes pensando en los estudiantes de grado con necesidades semejantes. 


\begin{tabular}{|c|c|}
\hline Concepto & $\begin{array}{l}\text { Puntuación/ } \\
\text { comentarios }\end{array}$ \\
\hline \multicolumn{2}{|l|}{ General } \\
\hline 1. Ubicación & $17 / 20$ \\
\hline $\begin{array}{l}\text { 1.1. ¿Responde adecuadamente a los requerimientos previstos / a las necesidades de los } \\
\text { usuarios? }\end{array}$ & 4.5 \\
\hline 1.2. ¿Está la biblioteca bien integrada dentro de la ciudad o del campus universitario? & 4.5 \\
\hline 1.3. ¿Tiene la forma del solar una influencia negativa en la organización del edificio? & 4 \\
\hline 1.4. ¿Está el edificio bien orientado en relación con la luz, el ruido exterior y el clima? & 4 \\
\hline 2. Accesibilidad & $24 / 45$ \\
\hline 2.1. ¿Se puede llegar a la biblioteca en transporte público? & 3 \\
\hline 2.2. ¿Hay suficientes plazas de aparcamiento para los usuarios (coche, moto, bicicleta)? & 2 \\
\hline $\begin{array}{l}\text { 2.3. ¿Existen barreras físicas para las personas (usuarios y personal) dentro de la biblio- } \\
\text { teca? }\end{array}$ & 3 \\
\hline $\begin{array}{l}\text { 2.4. ¿Han sido tanto el edificio como los interiores diseñados para permitir y posibilitar la } \\
\text { autonomía de las personas con discapacidad? }\end{array}$ & 3 \\
\hline 2.5. ¿Tiene la biblioteca un control de acceso / sistema de alarma electrónica? & 4 \\
\hline $\begin{array}{l}\text { 2.6. ¿Tiene el mobiliario barreras arquitectónicas? ¿Se impide o reduce la movilidad de } \\
\text { los usuarios? }\end{array}$ & 2 \\
\hline 2.7. ¿Cuenta la biblioteca con un sistema interno de señalización e información? & 3 \\
\hline 2.8. ¿Está la información en el edificio disponible en varios idiomas? & 3 \\
\hline 2.9. ¿Existen dispositivos multimedia de información y orientación? & 1 \\
\hline 3. Sostenibilidad & $20 / 65$ \\
\hline $\begin{array}{l}\text { 3.1. ¿Tiene la fachada del edificio una forma o diseño que favorezcan la eficiencia ener- } \\
\text { gética? }\end{array}$ & 3 \\
\hline 3.2. ¿Se ha tenido en cuenta la climatología local en el diseño de la biblioteca? & 3 \\
\hline $\begin{array}{l}\text { 3.3. ¿Fue analizado el solar antes de la construcción, incluyendo, por ejemplo, un estudio } \\
\text { del suelo, de la orientación solar, del viento y la lluvia? }\end{array}$ & 2 \\
\hline 3.4. ¿Utiliza la biblioteca energías renovables (geotérmica, solar, etc.)? & 0 \\
\hline 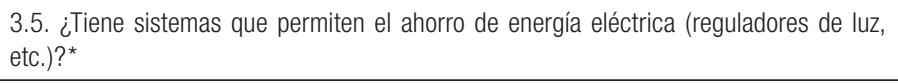 & 1 \\
\hline $\begin{array}{l}\text { 3.6. ¿Tiene la biblioteca alguna política de actuación para la reducción del consumo de } \\
\text { energía? }\end{array}$ & 1 \\
\hline $\begin{array}{l}\text { 3.7. ¿Tiene sistemas que permiten el ahorro de agua (grifos con cierre automático, depó- } \\
\text { sitos de los inodoros con agua de lluvia, etc.)? }\end{array}$ & 1 \\
\hline $\begin{array}{l}\text { 3.8. ¿Se utilizaron dispositivos en la construcción del edificio para evitar intercambios } \\
\text { térmicos y proporcionar suficiente aislamiento? }{ }^{\star}\end{array}$ & 3 \\
\hline 3.9. ¿Los interiores del edificio tienen luz natural? & 3 \\
\hline 3.10. ¿Es la iluminación artificial de bajo consumo? & 2 \\
\hline
\end{tabular}




\begin{tabular}{|c|c|}
\hline $\begin{array}{l}\text { 3.11. ¿Dispone de medidas para optimizar la luz del sol (paneles solares, claraboyas, con- } \\
\text { ductos solares, etc.)? }\end{array}$ & 1 \\
\hline 3.12. ¿Es posible la ventilación natural del edificio? & 0 \\
\hline 3.13. ¿Hay otras características que favorezcan la de sostenibilidad? & 0 \\
\hline 4. Seguridad y vigilancia & $45 / 75$ \\
\hline 4.1. ¿Ha habido problemas de seguridad en la biblioteca? & 1 \\
\hline 4.2. ¿Hay problemas de vandalismo? & 1 \\
\hline 4.3. ¿Dispone la biblioteca de personal de seguridad? & 2 \\
\hline $\begin{array}{l}\text { 4.4. ¿Dispone la biblioteca de instrucciones de seguridad y de los dispositivos de seguri- } \\
\text { dad en caso de incendio u otros peligros? }\end{array}$ & 4 \\
\hline $\begin{array}{l}\text { 4.5. ¿Hay salidas de emergencia para desalojar el edificio en caso de incendio u otros } \\
\text { peligros claramente visibles? }\end{array}$ & 4 \\
\hline $\begin{array}{l}\text { 4.6. ¿Tienen las salidas de emergencia una alarma acústica y visual para evitar el robo? } \\
\text { ¿Están conectadas estas alarmas a los puntos de trabajo del personal para que puedan } \\
\text { efectuar un adecuado control y, si es necesario, actuar? }\end{array}$ & 3 \\
\hline $\begin{array}{l}\text { 4.7. ¿Tiene la biblioteca un sistema de alarma de incendios? ¿Está conectado con el cuer- } \\
\text { po de bomberos local? ¿Cumple el sistema de seguridad de fuego la normativa nacional? }\end{array}$ & 5 \\
\hline 4.8. ¿Hay sistemas de extinción de incendios previstos conforme a la normativa?* & 4 \\
\hline 4.9. ¿Ha habido falsas alarmas? & 4 \\
\hline 4.10. ¿Se llevan a cabo regularmente simulacros de incendio y prácticas de evacuación? & 5 \\
\hline 4.11. ¿Existe un sistema de alarma anti-intrusión en el edificio? & 2 \\
\hline $\begin{array}{l}\text { 4.12. ¿Funciona la biblioteca con un único control de acceso en la entrada o hay varios } \\
\text { puntos de control? }\end{array}$ & 1 \\
\hline 4.13. ¿Existen medidas de seguridad de las colecciones? & 3 \\
\hline 4.14. ¿Tiene un sistema de control antirrobo el fondo documental?* & 3 \\
\hline $\begin{array}{l}\text { 4.15. ¿Dispone la biblioteca de taquillas para las pertenencias de los usuarios? ¿Necesi- } \\
\text { tan video vigilancia? }\end{array}$ & 3 \\
\hline 5. Flexibilidad & $16 / 25$ \\
\hline 5.1. ¿Son los espacios suficientemente flexibles para permitir cambios? & 4 \\
\hline 5.2. ¿Es posible ofrecer una variedad de servicios? & 4 \\
\hline 5.3. ¿Es posible ampliar el edificio en el futuro? & 2 \\
\hline $\begin{array}{l}\text { 5.4. ¿Es posible el uso de algunas áreas de la biblioteca fuera del horario normal de aper- } \\
\text { tura (salas polivalentes, aulas, etc.)? }\end{array}$ & 4 \\
\hline $\begin{array}{l}\text { 5.5. ¿Existen espacios exteriores que formen parte de la biblioteca? Si este es el caso, } \\
\text { ¿es posible entrar en ellos sin necesidad de pasar por el control de acceso (sistema de } \\
\text { alarma electrónica)? }\end{array}$ & 2 \\
\hline \multicolumn{2}{|l|}{ Edificio } \\
\hline 6. Área de acceso & $39 / 75$ \\
\hline 6.1. ¿Es la entrada a la biblioteca lo suficientemente visible? & 3 \\
\hline
\end{tabular}




\begin{tabular}{|c|c|}
\hline 6.2. ¿Es el sistema de puertas adecuado y funcional para todos los usuarios? & 2 \\
\hline 6.3. ¿Las puertas de acceso son automáticas? & 0 \\
\hline 6.4. ¿Dispone el sistema de puertas de protección contra la lluvia en la zona de entrada? & 5 \\
\hline 6.5. ¿Es adecuado el tamaño de la zona de entrada? & 5 \\
\hline 6.6. ¿Existe una relación visual entre el interior y el exterior del edificio? & 4 \\
\hline 6.7. ¿La organización del edificio es clara y comprensible desde la zona de entrada? & 1 \\
\hline $\begin{array}{l}\text { 6.8. Si se trata de un edificio multifuncional, ¿son visibles o están suficientemente señali- } \\
\text { zadas las principales áreas funcionales desde la zona de entrada? }\end{array}$ & 1 \\
\hline $\begin{array}{l}\text { 6.9. ¿Está la biblioteca bien organizada y es fácil llegar a cualquier área de la misma des- } \\
\text { de la zona de entrada? }\end{array}$ & 2 \\
\hline $\begin{array}{l}\text { 6.10. ¿Es posible la libre circulación a través de todos los espacios de la biblioteca (exte- } \\
\text { riores e interiores) habiendo un único control de acceso (sistema de alarma electrónica) } \\
\text { en la entrada? }\end{array}$ & 4 \\
\hline 6.11. ¿Son visibles las escaleras y ascensores desde la zona de entrada? & 4 \\
\hline $\begin{array}{l}\text { 6.12. ¿Hay un buzón de retorno de documentos que sea accesible las } 24 \text { horas del día y } 7 \\
\text { días a la semana? ¿Está bien situado? (Si se considera necesario) }{ }^{\star}\end{array}$ & 4 \\
\hline $\begin{array}{l}\text { 6.13. ¿Existen máquinas de autoservicio para el préstamo y el retorno? (Si se considera } \\
\text { necesario)* }\end{array}$ & 0 \\
\hline $\begin{array}{l}\text { 6.14. ¿Existen áreas de descanso y relación (butacas y mesas, máquinas expendedoras } \\
\text { de bebidas, etc.)? }\end{array}$ & 1 \\
\hline $\begin{array}{l}\text { 6.15. ¿Hay taquillas para las pertenencias de los usuarios en una buena situación (junto } \\
\text { a la entrada)?* }\end{array}$ & 3 \\
\hline 7. Materiales & $11 / 20$ \\
\hline $\begin{array}{l}\text { 7.1. ¿Son adecuados los materiales de construcción con respecto a la ubicación del edi- } \\
\text { ficio? }\end{array}$ & 4 \\
\hline $\begin{array}{l}\text { 7.2. ¿Los materiales utilizados en el exterior del edificio permitirían una remodelación del } \\
\text { mismo sin demasiadas complicaciones? }\end{array}$ & 3 \\
\hline $\begin{array}{l}\text { 7.3. ¿Los materiales de las que están hechas las escaleras públicas (metal, hormigón, } \\
\text { madera, etc.) provocan ruidos innecesarios?* }\end{array}$ & 3 \\
\hline $\begin{array}{l}\text { 7.4. ¿Los materiales utilizados para la construcción garantizan su mantenimiento en } \\
\text { buenas condiciones con el paso del tiempo? }\end{array}$ & 1 \\
\hline 8. Pavimentos & $22 / 35$ \\
\hline 8.1. ¿Es adecuado el pavimento que hay en la entrada del edificio?* & 4 \\
\hline 8.2. ¿Es adecuado el pavimento de las rampas y escaleras?* & 4 \\
\hline $\begin{array}{l}\text { 8.3. ¿Es adecuado el pavimento que hay en las áreas públicas de la biblioteca (área de } \\
\text { acceso, área general, etc.)?*}\end{array}$ & 4 \\
\hline 8.4. ¿Se han mantenido en buenas condiciones con el paso del tiempo? & 2 \\
\hline $\begin{array}{l}\text { 8.5. ¿Qué opinión se tiene sobre la durabilidad, la facilidad de limpieza y la absorción } \\
\text { acústica? }\end{array}$ & 2 \\
\hline
\end{tabular}




\begin{tabular}{|c|c|}
\hline $\begin{array}{l}\text { 8.6. ¿El material que se utiliza en las cajas de registro de las instalaciones que están colo- } \\
\text { cadas en el pavimento es el adecuado?*}\end{array}$ & 3 \\
\hline 8.7. ¿Cuál es la evaluación general de los pavimentos? & 3 \\
\hline 9. Revestimientos de techo & $3 / 10$ \\
\hline 9.1. ¿Hay algún elemento que actúe de aislante acústico en los techos? & 2 \\
\hline 9.2. ¿El falso techo es practicable? & 1 \\
\hline 10. Insonorización & $14 / 30$ \\
\hline 10.1. ¿Está suficientemente aislado el edificio ante la contaminación acústica exterior? & 2 \\
\hline 10.2. ¿Se quejan los usuarios del ruido en el interior del edificio? & 2 \\
\hline $\begin{array}{l}\text { 10.3. En caso afirmativo, ¿cuáles son las fuentes que producen ese ruido? [Sin puntua- } \\
\text { ción] }\end{array}$ & $\begin{array}{l}\text { Ferias que se } \\
\text { realizan en los } \\
\text { soportales de } \\
\text { la biblioteca. } \\
\text { Ruido de las } \\
\text { zonas comu- } \\
\text { nes que entra } \\
\text { en las salas. }\end{array}$ \\
\hline 10.4. ¿Ofrece alternativas la biblioteca ante las Ilamadas a través de teléfonos móviles?* & 2 \\
\hline 10.5. ¿Es suficiente el aislamiento acústico entre las diferentes zonas? & 2 \\
\hline $\begin{array}{l}\text { 10.6. ¿Están las zonas del edificio organizadas de manera que los usuarios accedan pri- } \\
\text { mero a las áreas más ruidosas, estando más alejadas las áreas silenciosas? }\end{array}$ & 4 \\
\hline $\begin{array}{l}\text { 10.7. ¿Hay elementos de absorción acústica en techos, revestimientos de paredes, sue- } \\
\text { los, cortinas y/o muebles? }\end{array}$ & 2 \\
\hline 11. Aberturas & $19 / 40$ \\
\hline 11.1. ¿Las aberturas proporcionan una buena y suficiente iluminación natural? & 5 \\
\hline 11.2. ¿Hay entradas de luz que provoquen reflejos? & 2 \\
\hline $\begin{array}{l}\text { 11.3. ¿Existen sistemas de protección contra los rayos del sol (cornisas, persianas, corti- } \\
\text { nas, láminas solares, etc.)? }\end{array}$ & 1 \\
\hline 11.4. ¿Las dimensiones y la ubicación de las aberturas provocan problemas térmicos? & 2 \\
\hline 11.5. ¿Las dimensiones y la ubicación de las aberturas provocan problemas acústicos? & 2 \\
\hline $\begin{array}{l}\text { 11.6. ¿Las dimensiones y ubicación de aberturas garantizan la seguridad contra acciden- } \\
\text { tes? }\end{array}$ & 4 \\
\hline 11.7. ¿Es posible tener una ventilación natural? & 1 \\
\hline $\begin{array}{l}\text { 11.8. ¿Cuál es el sistema de apertura (mecanismo manual, control remoto, etc.)? [Sin } \\
\text { puntuación] }\end{array}$ & $\begin{array}{l}\text { En los casos } \\
\text { que son prac- } \\
\text { ticables. es de } \\
\text { forma manual }\end{array}$ \\
\hline $\begin{array}{l}\text { 11.9. Cuando el sistema de apertura funciona con mecanismos manuales, ¿pueden ser } \\
\text { bloqueados para garantizar que los usuarios no puedan manipularlos? }\end{array}$ & 2 \\
\hline 12. Iluminación artificial & $10 / 30$ \\
\hline 12.1. ¿Hay una intensidad de iluminación suficiente? & 3 \\
\hline
\end{tabular}




\begin{tabular}{|c|c|}
\hline $\begin{array}{l}\text { 12.2. ¿La iluminación artificial proviene del techo, de las paredes o está incorporada en el } \\
\text { mobiliario? [Sin puntuación] }\end{array}$ & Techo \\
\hline 12.3. ¿Cuál es el "color" de la luz (cálido, frío)? [Sin puntuación] & Frío \\
\hline $\begin{array}{l}\text { 12.4. ¿Puede el personal bibliotecario controlar la iluminación de forma independiente } \\
\text { (encender y apagar las luces en cada área de actividad)? }\end{array}$ & 3 \\
\hline $\begin{array}{l}\text { 12.5. ¿Existe algún sistema de regulación automática en función de la entrada de luz na- } \\
\text { tural? }\end{array}$ & 0 \\
\hline 12.6. ¿Proporciona la iluminación artificial ambientes diferenciados y confortables? & 1 \\
\hline 12.7. ¿La iluminación en los baños funciona con detectores de presencia? & 0 \\
\hline 12.8. ¿Es posible accionar todas las luces de encendido/apagado desde un único punto? & $\begin{array}{l}\text { (Sí. por } \\
\text { salas) } 3\end{array}$ \\
\hline 13. Mobiliario & $29 \% 55$ \\
\hline 13.1. ¿Es nuevo el mobiliario de la biblioteca? & 2 \\
\hline $\begin{array}{l}\text { 13.2. ¿Cumple el mobiliario los requerimientos básicos (calidad, durabilidad, funcionali- } \\
\text { dad, movilidad, ergonomía, estética, etc.)? }\end{array}$ & 2 \\
\hline $\begin{array}{l}\text { 13.3. ¿Está el mobiliario bien diseñado (calidad, durabilidad, funcionalidad, movilidad, er- } \\
\text { gonomía, estética, etc.)? }\end{array}$ & 3 \\
\hline 13.4. ¿Es adecuado para todos los usuarios? & 3 \\
\hline 13.5. ¿Es el mobiliario resistente al uso intensivo? & 3 \\
\hline 13.6. ¿Es adecuado y ergonómico el tamaño de mesas, sillas y demás mobiliario? & 3 \\
\hline 13.7. ¿Tiene la biblioteca todos los muebles necesarios (expositores, etc.)? & 2 \\
\hline $\begin{array}{l}\text { 13.8. ¿Está diseñado el mobiliario por el arquitecto o se ha comprado a través de un pro- } \\
\text { veedor? [Sin puntuación] }\end{array}$ & Proveedor \\
\hline 13.9. ¿Cuál es la opinión de los materiales utilizados en las sillas, sillones, mesas, etc.? & 3 \\
\hline 13.10. ¿Son adecuadas las distancias que hay entre los diferentes muebles? & 3 \\
\hline $\begin{array}{l}\text { 13.11. ¿Provoca sensación de fatiga visual (organización de los muebles, dimensio- } \\
\text { nes, color, materiales, etc.)? }\end{array}$ & 3 \\
\hline $\begin{array}{l}\text { 13.12. ¿Cuál es la impresión general sobre la estética del conjunto de muebles (color, } \\
\text { material, etc.)? }\end{array}$ & 2 \\
\hline 14. Calefacción, ventilación y aire acondicionado & $6 / 15$ \\
\hline $\begin{array}{l}\text { 14.1. ¿Qué tipo de tratamiento de aire tiene la biblioteca: calefacción / aire acondiciona- } \\
\text { do? [Sin puntuación] }\end{array}$ & Ambos \\
\hline $\begin{array}{l}\text { 14.2. ¿Funcionan estos sistemas de forma independiente para cada área de actividad } 0 \\
\text { hay un sistema centralizado para toda la biblioteca? }\end{array}$ & $\begin{array}{r}\text { (Parcialmen- } \\
\text { te) } 2\end{array}$ \\
\hline $\begin{array}{l}\text { 14.3. ¿El sistema de calefacción / aire acondicionado proporciona un entorno de trabajo } \\
\text { confortable (uniformidad ambiental, ruido, renovación de aire, etc.)? }\end{array}$ & 2 \\
\hline 14.4. ¿Cuál es la evaluación general de la climatización? & 2 \\
\hline 15. Instalaciones alimentadas por un sistema de cableado & $15 / 35$ \\
\hline 15.1. ¿Dónde está situada la centralización? ¿Es inaccesible para el público? & 4 \\
\hline
\end{tabular}




\begin{tabular}{|c|c|}
\hline 15.2. ¿Por dónde pasan las canalizaciones (techo, suelo, paredes)? [Sin puntuación] & $\begin{array}{r}\text { (Techo. suelos } \\
\text { y paredes) }\end{array}$ \\
\hline 15.3. ¿Es fácil acceder a las canalizaciones (reparaciones, ampliaciones)? & 2 \\
\hline 15.4. ¿Ofrece el sistema de canalizaciones la posibilidad de ampliación? & 2 \\
\hline $\begin{array}{l}\text { 15.5. ¿Es suficiente el número de enchufes (enchufes de corriente normal, informática, } \\
\text { etc.) tanto para el personal bibliotecario como para los usuarios? }\end{array}$ & 1 \\
\hline 15.6. ¿Está el sistema de cableado ordenado y bien protegido? & 3 \\
\hline 15.7. ¿Está el auditorio suficientemente equipado para todas las actividades previstas? & 2 \\
\hline $\begin{array}{l}\text { 15.8. ¿Cuál es la evaluación general de las instalaciones alimentadas por un sistema de } \\
\text { cableado? }\end{array}$ & 3 \\
\hline 16. Datos & $21 / 30$ \\
\hline 16.1. ¿Dónde está situado el servidor? & (En un CPD) 5 \\
\hline $\begin{array}{l}\text { 16.3. ¿La infraestructura de datos está preparada para soportar el crecimiento progresivo } \\
\text { en el uso de dispositivos móviles? }\end{array}$ & 4 \\
\hline $\begin{array}{l}\text { 16.4. ¿Dispone la biblioteca de un sistema que garantice las copias de seguridad de la } \\
\text { información? }\end{array}$ & 5 \\
\hline 16.5. ¿Existe un sistema de megafonía para toda la biblioteca? & 0 \\
\hline 16.6. ¿Ofrece la biblioteca el acceso W-LAN? & 3 \\
\hline 17. Zonas logísticas (sanitarios, cuartos de limpieza y de instalaciones, etc.) & $29 / 60$ \\
\hline 17.1. ¿Hay suficientes sanitarios? & 3 \\
\hline 17.2. ¿Están bien situados? & 2 \\
\hline 17.3. ¿Hay suficientes sanitarios adaptados para personas con discapacidad? & 2 \\
\hline 17.4. ¿Se produce vandalismo por parte de los usuarios? & 1 \\
\hline $\begin{array}{l}\text { 17.5. ¿Están bien equipados los sanitarios (dispensadores de jabón, secadores de } \\
\text { manos, cambiadores de pañales, papel higiénico, colgadores en los lavabos, etc.)? }\end{array}$ & 2 \\
\hline 17.6. ¿Se estropean con frecuencia (cadena del WC, atascos, etc.)? & 2 \\
\hline 17.7. ¿Qué tipo de pavimento hay? & (Loseta) 4 \\
\hline 17.8. ¿Qué materiales de acabado hay en las paredes? & $\begin{array}{r}\text { (Alicatado } \\
\text { con cierta } \\
\text { rugosidad) } 3\end{array}$ \\
\hline 17.9. ¿Qué tipo de techo hay? & (Escayola) 3 \\
\hline 17.10. ¿De qué material son las puertas? & $\begin{array}{r}\text { (Contrachapa- } \\
\text { do) } 2\end{array}$ \\
\hline $\begin{array}{l}\text { 17.11. ¿Hay en cada planta un vertedero para llenar y vaciar cubos de agua para la lim- } \\
\text { pieza? }\end{array}$ & 1 \\
\hline 17.12. ¿Cuál es la evaluación general de los materiales de acabado utilizados? & 3 \\
\hline \multicolumn{2}{|l|}{ Servicios } \\
\hline 18. Áreas de servicio & $11 / 25$ \\
\hline
\end{tabular}




\begin{tabular}{|c|c|}
\hline 18.1. ¿Hay áreas de la biblioteca destinadas a la interacción con los usuarios?* & $\begin{array}{r}\text { (Mostrado- } \\
\text { res) } 2\end{array}$ \\
\hline 18.2. ¿Está centralizado el servicio de préstamo? [Sin puntuación] & No \\
\hline 18.3. ¿Dispone la biblioteca de mostrador de recepción? & $\begin{array}{r}\text { (Conserje- } \\
\text { ría) } 1\end{array}$ \\
\hline $\begin{array}{l}\text { 18.4. ¿Hay un espacio específico para la reprografía (fotocopiar, escanear, imprimir, } \\
\text { etc.)? }\end{array}$ & 2 \\
\hline 18.5. ¿Hay mostradores de información en las diferentes áreas de la biblioteca? & 3 \\
\hline 18.6. ¿Están todas las áreas de servicio debidamente ubicadas y conectadas? & 3 \\
\hline 19. Áreas para los usuarios & $13 / 30$ \\
\hline 19.1. ¿Hay un número suficiente de puntos de consulta? & 4 \\
\hline $\begin{array}{l}\text { 19.2. ¿Hay suficiente variedad de asientos? ¿Qué tipos de asientos hay? (Trabajo normal, } \\
\text { trabajo con ordenador, estudio, lectura, audición, información y consulta rápida, estudio } \\
\text { en grupo, salas de formación, cabinas, trabajo multimedia, descanso y relación, mesa con } \\
\text { sillones, butacas de auditorio, etc.) }\end{array}$ & 2 \\
\hline 19.3. ¿Hay suficientes zonas de estudio en grupo? & 3 \\
\hline 19.4. ¿Hay espacios destinados al trabajo concentrado / estudio? & 2 \\
\hline $\begin{array}{l}\text { 19.5. ¿Pueden los usuarios mover y reorganizar los muebles en función de sus necesida- } \\
\text { des? }\end{array}$ & 1 \\
\hline 19.6. ¿Existe una separación adecuada entre los diferentes tipos de puntos de consulta? & 1 \\
\hline 20. Espacio para los estudiantes* & $24 / 65$ \\
\hline 20.1. ¿Es adecuada la dimensión para la población de la comunidad / estudiantes? & 3 \\
\hline 20.2. ¿Es atractivo el mobiliario y se adecua el gusto y las necesidades de los jóvenes? & 1 \\
\hline $\begin{array}{l}\text { 20.3. ¿Se adaptan las estanterías a la variedad de formatos del fondo documental (no } \\
\text { ficción, música, DVD, libros en CD o MP3, revistas, cómics, novelas gráficas, etc.)? }\end{array}$ & 3 \\
\hline $\begin{array}{l}\text { 20.4. ¿Proporciona el espacio un ambiente agradable y confortable para el estudio, la } \\
\text { relación y otras actividades de ocio? }\end{array}$ & 2 \\
\hline $\begin{array}{l}\text { 20.5. ¿Se han tenido en cuenta a los jóvenes en la planificación, diseño, implementación, } \\
\text { mantenimiento y promoción de este espacio? }\end{array}$ & 1 \\
\hline 20.6. ¿Es el espacio cómodo, alegre y agradable de acuerdo a los gustos de los jóvenes? & 3 \\
\hline 20.7. ¿Es el espacio interactivo, flexible, y ofrece variedad de la tecnología? & 2 \\
\hline $\begin{array}{l}\text { 20.8. ¿Existe algún tipo de característica o efecto especial con el fin de atraer al público } \\
\text { joven? }\end{array}$ & 0 \\
\hline 20.9. ¿Se ofrece la variedad necesaria de asientos y espacios de trabajo? & 2 \\
\hline $\begin{array}{l}\text { 20.10. ¿Los espacios permiten el trabajo en grupo, el estudio en solitario, sentarse en el } \\
\text { suelo y disponer de intimidad? }\end{array}$ & 2 \\
\hline 20.11. ¿Hay suficiente espacio para poder programar actividades con grupos? & 2 \\
\hline $\begin{array}{l}\text { 20.12. ¿Están música y el arte (elementos importantes de la cultura adolescente) incor- } \\
\text { porados en el diseño del espacio y en los servicios que se ofrecen? }\end{array}$ & 0 \\
\hline 20.13. ¿El pavimento escogido garantiza su durabilidad? & 3 \\
\hline
\end{tabular}




\begin{tabular}{|c|c|}
\hline 21. Zonas de trabajo interno & $22 / 45$ \\
\hline 21.1. ¿Están bien situadas para poder ofrecer los servicios? & 3 \\
\hline 21.2. ¿Son adecuadas para cumplir con los fines previstos? & 3 \\
\hline 21.3. ¿Tienen la dimensión suficiente? & 3 \\
\hline $\begin{array}{l}\text { 21.4. ¿Disponen de todos los ámbitos necesarios para el descanso (sala de estar, cocina, } \\
\text { etc.)? }\end{array}$ & 2 \\
\hline 21.5. ¿Dispone la biblioteca de sanitarios específicos para el personal bibliotecario? & $\begin{array}{r}\text { (En planta } \\
\text { baja) } 2\end{array}$ \\
\hline $\begin{array}{l}\text { 21.6. ¿Cómo se organizan las zonas de trabajo (planta abierta, oficinas separadas, etc.)? } \\
\text { [Sin puntuación] }\end{array}$ & $\begin{array}{l}\text { Depende } \\
\text { de la zona }\end{array}$ \\
\hline 21.7. ¿Los ámbitos de trabajo son ergonómicos y funcionales? & 3 \\
\hline 21.8. ¿Disponen de iluminación natural? & 2 \\
\hline 21.9. ¿Hay una entrada independiente para el personal?* & 4 \\
\hline 21.10. ¿Dispone la biblioteca de plazas de aparcamiento para el personal? & 0 \\
\hline 22. Mantenimiento & $60 / 20$ \\
\hline 22.1. ¿Es el edificio fácil de limpiar (suelos, sanitarios, etc.)? & 2 \\
\hline $\begin{array}{l}\text { 22.2. ¿Es el adecuado mantenimiento que se efectúa (limpieza, reparaciones, revisiones, } \\
\text { etc.)? }\end{array}$ & 1 \\
\hline 22.3. ¿Las dimensiones y la ubicación de las aberturas causan problemas de limpieza? & 1 \\
\hline 22.4. ¿Son las instalaciones de fácil acceso? & 2 \\
\hline \multicolumn{2}{|l|}{ Conclusión } \\
\hline 23. Si se pidieran tres deseos sobre el edificio, ¿cuáles serían? & $\begin{array}{r}\text { Véanse las } \\
\text { conclusiones } \\
\text { de la anterior } \\
\text { valoración }\end{array}$ \\
\hline 24. ¿Hay alguna cosa que convendría cambiar? & $\begin{array}{r}\text { Véanse las } \\
\text { conclusiones } \\
\text { de la anterior } \\
\text { valoración }\end{array}$ \\
\hline 25. ¿Hay alguna cosa que sea particularmente satisfactoria? & $\begin{array}{r}\text { Véanse las } \\
\text { conclusiones } \\
\text { de la anterior } \\
\text { valoración }\end{array}$ \\
\hline PUNTUACIÓN TOTAL & $416 / 850$ \\
\hline PUNTUACIÓN PORCENTUAL & $48.94 \%$ \\
\hline PUNTUACIÓN MEDIA & 2.45 \\
\hline
\end{tabular}

Tabla III. Cuestionario IFLA de evaluación de edificios de biblioteca 


\section{Comparando los dos MODElos}

Tras realizar la valoración del mismo espacio con ambos sistemas se extraen una serie de conclusiones sobre su viabilidad. Ambos sistemas son viables y aplicables de forma más o menos sencilla por cualquier bibliotecario o persona interesada en estos temas, aunque por su concepción están pensados más desde un punto de vista bibliotecario y un arquitecto que los usase requeriría de experiencia previa en estos ámbitos, sobre todo en el cuestionario IFLA cuando se refiere a servicios.

El cuestionario de la IFLA es evidentemente más prolijo, aunque con la flexibilidad de poder usar sólo las cuestiones que nos interesen. Su desarrollo de los temas es más detallado. Valora no sólo el edificio, sino también en gran medida el funcionamiento de la biblioteca, sus servicios, aunque se pongan en relación con la infraestructura. Digamos que se centra más en aspectos funcionales, mientras que el formulario propio resulta más conceptual, orientándose a los espacios.

Ambos formularios están sujetos a una gran subjetividad. En esto, el formulario IFLA deja algunos aspectos totalmente abiertos a la interpretación: se señala si el edificio tiene A o B, pero es la persona que lo está cumplimentando el que tiene que decidir si eso es bueno o malo sobre el terreno, aunque a veces con la propia formulación de la pregunta sugiere si esto es positivo o negativo. Mientras, el carácter más conceptual que señalamos del formulario propio requiere de experiencia y conocimientos de otras realidades para ser verdaderamente efectivo.

La longitud y detalle del formulario IFLA quizás lo haga más complejo de utilizar, pero es eficaz como listado de comprobación de un edificio que visitamos para extraer conclusiones de su funcionamiento que podamos aplicar a otros centros. Al fin y al cabo esta es su misión principal, que cumple. Creemos que esta orientación conlleva que su uso como herramienta de evaluación general no sea tan eficaz: quiere destacar defectos y buenas prácticas, no tanto valorar el edificio en su conjunto. En esto, su utilización para evaluar proyectos resulta más difícil y creemos que en esto es más conveniente el formulario propio.

Finalmente, si comparamos las puntuaciones vemos que, en el caso de cuestionario IFLA, son ligeramente más bajas. Aún dentro de lo aceptable, no llega al aprobado: 416 puntos sobre 850 posibles, lo que supone un 48.94 sobre 100 o una media de 2.45. Recordemos que antes obtuvo 2.68. Esto probablemente se debe a que, aunque conceptualmente es una biblioteca con bastantes aspectos positivos, lo cual es valorado en la encuesta propia, su realización (por ejemplo los acabados) y algunos aspectos funcionales se ven castigados en el cuestionario IFLA. 
En resumen, el uso de uno de los dos modelos y sus formularios no resulta excluyente del otro, pudiendo llegar a ser complementarios. Para asegurar su efectividad, ambos deberían ser usados por bibliotecarios o estudiosos con unos mínimos conocimientos sobre infraestructuras bibliotecarias, sobre todo en lo que hace al conocimiento directo y empírico de una diversidad de edificios, cuanto más amplia mejor. Con ello, se puede alcanzar la necesaria subjetividad y contar con unos instrumentos de evaluación de gran valor y capacidad, que nos permitirían además establecer comparaciones entre semejantes.

En esto, el modelo basado en Faulkner-Brown permite una mejor evaluación del edificio como concepto y de su previsible comportamiento a largo plazo al demostrar unas cualidades naturales. Así, resulta más sencilla su utilización en la evaluación previa, sobre proyecto. Mientras, el de la IFLA funciona mejor como una lista de comprobación de un centro, especialmente en una POE, que para la evaluación conceptual. Señala si el edificio tiene un funcionamiento correcto, como una máquina, de acuerdo a la concepción contemporánea de la biblioteca, y permite usar estos datos para su comparación con otros centros.

\section{Conclusiones}

Si tenemos claro que los edificios, como cualquier otro recurso de la biblioteca, pueden y deben ser medidos en su eficiencia y, por tanto, son susceptibles de ser evaluados, sorprende el relativamente escaso aparataje disponible al efecto, habiendo pocos estudios empíricos sobre el uso de las nuevas estructuras hasta fecha bien reciente.

Ante esto, se pueden aplicar cualquiera de los dos modelos presentados de forma bastante efectiva. Se puede realizar una evaluación guiándose en una serie de criterios objetivos y probados, presentados en formato de encuesta o formulario y ayudándose de la comparación y la experiencia. Aun basándose en estas pautas objetivas, los resultados obtenidos estarán teñidos indefectiblemente por la subjetividad al ser, al fin y al cabo, opiniones. Por ello, será necesario un mínimo de experiencia y conocimientos para conseguir un cierto grado de objetividad.

Para conseguir una mayor objetividad se podrían utilizar estos cuestionarios a modo de encuesta, intentando recoger una muestra mayor de opiniones. Sin embargo, éstas no dejarían de ser subjetivas, con la desventaja de proceder de personas sin conocimientos ni experiencia específicas. Por ello, sería recomendable incidir en esa experiencia y completar cualquiera de los 
dos cuestionarios con datos numéricos de comparación con semejantes y con las normas.

Ambos cuestionarios son utilizables, como se comprueba en el artículo, para estos fines, aunque resulta quizás más cercano a los objetivos iniciales el propio, mientras que el otro requiere una adaptación y es más útil en su concepción originaria, como formulario o lista de control en una evaluación postocupacional.

\section{REFERENCIAS}

Bellini, Paolo. 2000. "Structures and infrastructures of university libraries in the computer era: current trends". Bollettino AIB 40 (3): 331-346.

Bisbrouck, M. F. 2000. "Les bibliothèques universitaires: l'évaluation des nouveaux bâtiments”. Bulletin des Bibliothèques de France 45 (3): 31-38. http://www.enssib. $\mathrm{fr} /$ bibliotheque-numerique/documents/36409-les-bibliotheques-universitaires. pdf

Black, Alistair y Nan Dahlkild 2011. "Introduction”. Library Trends 60 (1): 1-10. http://dx.doi.org/10.1353/lib.2011.0025

Boekhors, Peter T. y Ulrike Scholle. 2002. "Editorial”. Liber Quarterly 12: 5-6. http://liber.library.uu.nl/index.php/lq/article/viewFile/7662/7698

Buckland, Michael. 1992. Redesigning library services: a manifesto. Chicago and London: American Library Association. http://ucblibrary3.berkeley.edu/Literature/ Library/Redesigning/

Carrión Gútiez, Manuel. 2001. Manual de biblioteca, 2a. ed. Madrid: Fundación Germán Sánchez Ruipérez.

Domínguez Martínez, Juan Carlos. 2002. “Nuevas tendencias en infraestructuras de bibliotecas universitarias". En Temas de biblioteconomía universitaria y general, J. A. Magán Wals (coord.), 611-635. Madrid: Editorial Complutense.

Edwards, Brian y B. Fisher. 2002. Libraries and Learning Resources Centres, 39-41. Oxford: Architectural Press.

Enright, Suzanne. 2002. "Post Occupancy Evaluation of UK Library Building Projects: Some Examples of Current Activity”. Liber Quarterly 12 (1): 26-45. http:// liber.library.uu.nl/index.php/lq/article/view/7665

Forrest, Charles y S. Bostick. 2012. "Welcoming, flexible, and state-of-the-art: approaches to continuous facilities improvement". En IFLA World Library and Information Congress. 78th IFLA General Conference and Assembly. 11-17 August 2012, Helsinki, Finland. Conference Session 190. Library Buildings and Equipment. Making the case for change through evaluation: post-occupancy evaluation of library buildings. http://conference.ifla.org/sites/default/files/files/papers/wlic2012/190-forrest-en.pdf

Fuentes Romero, Juan José. 1999. Evaluación de bibliotecas y centros de documentación e información. Gijón: Trea.

Gallo Léon, José Pablo. 2012. "Forma y función de los edificios de bibliotecas universitarias: Herramientas para su evaluación”. Tesis doctoral. Universidad de Murcia, Murcia, España. http://www.tesisenred.net/handle/10803/80598 
García Caro, Concha. 2005. "Propuesta de método de evaluación de sistemas bibliotecarios y de sus servicios". Boletín de la ANABAD 55 (1-2): 135-149.

Hebert, Paulette R. y Sylvia Chaney. 2012. "Using end-user surveys to enhance facilities design and management". Facilities 30 (11-12): 458-471. http://dx.doi. org/10.1108/02632771211252306

IFLA World Library and Information Congress. 78th IFLA General Conference and Assembly. 11-17 August 2012, Helsinki, Finland. Conference Session 190. Library Buildings and Equipment. Making the case for change through evaluation: post-occupancy evaluation of library buildings. http://conference.ifla.org/sites/default/files/files/papers/wlic2012/190-millan-en.pdf

IFLA. Library Buildings and Equipment Section. 2013. Questionnaire on Post-Occupancy Evaluation of Library buildings. La Haya: IFLA. http://www.ifla.org/ publications/questionnaire-on-post-occupancy-evaluation-of-library-buildings En español: http://www.ifla.org/files/assets/library-buildings-and-equipment/ Publications/post-occupancy_evaluation_-_spanish_version_27-11-13.pdf

Játiva Miralles, María Victoria. 2004. "Indicadores de calidad aplicables al análisis, evaluación y comparación de opacs”. El profesional de la información 13 (1): 28 46. http://dx.doi.org/10.1076/epri.13.1.28.29023

Khan, Ayub. 2009. Better by Design: An introduction to planning and designing a new library building. London: Facet Publishing.

Krempe, C. 2002. "Neubau der British Library St. Pancras: Anspruch und Realität". Berliner Handreichungen zur Bibliothekswissenschaft 106. http://www.ib.hu-berlin.de/ kumlau/handreichungen/h106/

Library Journal. 2011. "LJ's New Landmark Libraries: Criteria and Judges”. Library Journal. Spring. http://www.libraryjournal.com/lj/ljinprintcurrentissue/890311-403/criteria_and_judges.html.csp

Lindauer, Bonnie Gratch. 1998. "Defining and measuring the library's impact on campuswide outcomes”. College E Research Libraries 59 (6): 546-570. http://dx.doi. org/10.5860/crl.59.6.546 Trad. al castellano: Pasadas Ureña, C. 2000. "Definición y medida del impacto de las bibliotecas universitarias sobre los resultados globales de la institución”. Boletín de la Asociación Andaluza de Bibliotecarios 15 (59): 35-76.

Lippincott, Joan K. 2006. "Assessing Learning Spaces”. Proceedings of Library Assessment Conference, Building Effective, Sustainable, Practical Assessment. Virginia: Charlottesville, 251-257. http://www.arl.org/arldocs/stats/statsevents/ laconf/2006/Lippincott.ppt

Mason, Ellsworth. 1980. Mason on Library Buildings. Metuchen, London: The Scarecrow Press.

Matthews, G. 2013. "Evaluation of Space and Use: introduction”. En University Libraries and Space in the Digital World, G. Mathews y G. Walton (eds.), 167-170. Farnham: Ashgate

McDonald, Andrew. 2001. "Algunes questions sobre l'equipament i el disseny dels centres de recursos per a l'aprenentatge". En El desenvolupament de centres de recursos per a l'aprenentatge pel futur, 4-20. [Barcelona]: Consorci de Biblioteques Universitàries de Catalunya.

McDonald, Andrew. 2006. "The Ten Commandments revisited: the Qualities of Good Library Space”. Liber Quarterly 16 (2). http://liber.library.uu.nl/index. $\mathrm{php} / \mathrm{lq} /$ article/view/7840/8011

110

McDonald, Andrew. 2007. "How as it for you? The building process in practice". En IFLA Library Building Guidelines: Developments \& Reflections, Karen Latimer y 
Hellen Niegaard (eds.), 96-112. Munich: K.G. Saur.

Miettinen, Virve. 2013. "The future library designed with you". Scandinavian Public Library Quarterly 46 (2): 7-9. http://slq.nu/?cover=volume-46-no-2-2013

Mittler, Elmar. 2008. "The German Experience: Evaluation of German Library Buildings from the Last Decades”. Liber Quarterly 18 (2): 170-198. http://liber.library.uu.nl/index.php/lq/article/view/7920

Nitecki, Danuta A. 2011. "Space assessment as a venue for defining the academic library”. Library Quarterly 81 (1): 27-59. http://dx.doi.org/10.1086/657446

Oldenburg, Ray. 1989. The Great Good Place: Cafes, Coffee Shops, Community Centers, Beauty Parlors, General Stores, Bars, Hangouts, and How They Get You Through the Day. New York: Paragon House.

Oldenburg, Ray. 1991. The Great Good Place. New York: Marlowe \& Company.

Oldenburg, Ray. 2000. Celebrating the Third Place: Inspiring Stories about the "Great Good Places" at the Heart of Our Communities. New York: Marlowe \& Company.

Preiser, Wolfgang. 1995. "Post-Occupancy Evaluation: how to make buildings work better”. Facilities 13 (11): 19-28. http://dx.doi.org/10.1108/02632779510097787

REBIUN. 1999. Normas y directrices para las bibliotecas universitarias y cientificas, 2a. ed. aum. Madrid: Dirección general del Libro, Archivos y Bibliotecas.

REBIUN. 2000. Informe del grupo de trabajo sobre instalaciones bibliotecarias universitarias (inédito). Presentado en la Asamblea REBIUN, 2000. https://eciencia.urjc.es/bitstream/handle/10115/4345/informe\%20rebiun.pdf

Roberts, S. y M. Weaver. 2006. "Spaces for Learners and Learning: Evaluating the Impact of Technology-Rich Learning Spaces”. New Review of Academic Librarianship 12 (2): 95-107. http://dx.doi.org/10.1080/13614530701330380

Schlipf, Frederick y J. Moorman. 1998. Seven deadly sins of public library architecture. http://lis60001-access2information-drr.iwiki.kent.edu/file/view/7+deadly+sins+of+public+library+architetcure.pdf

Shill, Harold B. y S. Tonner. 2004. "Does the Building Really Matter? Usage Patterns in New, expanded and renovated libraries, 1995-2002". College E Research Libraries (March): 123-150. http://dx.doi.org/10.5860/crl.65.2.123

Vélez Salas, C. 2002. "Criterios y procedimientos para la remodelación, ampliación o adaptación de edificios para bibliotecas universitarias”. Información: producción, comunicación y servicios 12 (50): 6-14. http://www.infoconsultores.com.mx/RevInfo50/50_ART_Remodelacion.pdf

Para citar este texto:

Gallo-León, José Pablo. 2017. "La evaluación de infraestructuras y edificios de biblioteca: Faulkner-Brown frente al cuestionario de la IFLA". Investigación Bibliotecológica: Archivonomía, Bibliotecología e Información 72 (31): 81-111.

http://dx.doi.org/10.22201/iibi.0187358xp.2017.72.57825 